\title{
Sperm quality but not relatedness predicts sperm competition success in threespine sticklebacks (Gasterosteus aculeatus)
}

\author{
Marion Mehlis, Anna K Rahn and Theo C M Bakker
}

\begin{abstract}
Background: Mating between close relatives often leads to a reduction of an individual's fitness, due to an increased expression of deleterious alleles. Thus, in many animal taxa pre- as well as postcopulatory inbreeding avoidance mechanisms have evolved. An increased risk of inbreeding and hence a loss of genetic variation may occur during founder events as in most cases only few individuals establish a new population. The threespine stickleback (Gasterosteus aculeatus) is a small externally fertilizing fish species subject to strong sperm competition. Sticklebacks inhabit both marine and freshwater environments and anadromous populations have repeatedly established new genetically less diverse freshwater populations. Previous studies showed that anadromous sticklebacks strongly suffer from inbreeding depression and when given the choice females prefer to mate with unrelated males.

Results: The present study aimed to address whether there exists a postcopulatory inbreeding avoidance mechanism solely based on sperm-egg interactions in sperm competition experiments. We used F1 individuals that originated either from a large, genetically heterogeneous anadromous population or from a small, genetically less diverse freshwater population. For each population, eggs of two different females were in vitro fertilized by the same two males' sperm in a paired study design. In the main experiment one male was the female's full-sib brother and in the control experiment all individuals were unrelated. The results revealed that fertilization success was independent of relatedness in both populations suggesting a general lack of a postcopulatory inbreeding avoidance mechanism. Instead, male quality (i.e. sperm morphology) predicted paternity success during competitive fertilization trials.
\end{abstract}

Conclusion: In sticklebacks, there is no evidence for postcopulatory inbreeding avoidance. Sperm morphology predicted paternity instead, thus sperm quality traits are under strong sexual selection, presumably driven by the high risk of sperm competition under natural conditions.

Keywords: Cryptic female choice, Fish, Paternity, Inbreeding avoidance, Inbreeding depression, Mate choice, Sexual selection, Sperm-egg interaction

\section{Background}

In many animal species a reduction of heterozygosity due to inbreeding often results in detrimental consequences for an individual's fitness (termed "inbreeding depression", [1]), for example by depressing a male's sperm competitiveness $([2]$, but see $[3,4])$. Beyond that inbreeding may also affect population performance (see [5] for details) and especially small populations with low

\footnotetext{
*Correspondence: mmehlis@evolution.uni-bonn.de

Institute for Evolutionary Biology and Ecology, University of Bonn, An der Immenburg 1, D-53121 Bonn, Germany
}

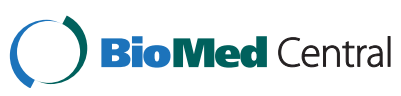

(c) 2015 Mehlis et al.; licensee BioMed Central. This is an Open Access article distributed under the terms of the Creative Commons Attribution License (http://creativecommons.org/licenses/by/4.0), which permits unrestricted use, distribution, and reproduction in any medium, provided the original work is properly credited. The Creative Commons Public Domain Dedication waiver (http://creativecommons.org/publicdomain/zero/1.0/) applies to the data made available in this article unless otherwise stated. genetic diversity face an increased risk of becoming extinct (see [6-9] and citations therein).

Precopulatory inbreeding avoidance mechanisms, such as sex-biased dispersal, delayed maturation, mate choice or extra-pair copulations, are well studied (see [10] for an overview). In species in which relatives are likely to encounter each other during adulthood, the ability to recognize kin is a prerequisite to avoid incestuous matings, which was described for various taxa [11-14]. However, if it is not possible to avoid incestuous matings, postcopulatory inbreeding avoidance mechanisms may have been alternatively developed. In some internally fertilizing species, for example, multiply-mated females

unless otherwise stated. 
avoided the negative costs of inbreeding by cryptically favoring the sperm of unrelated males [15-24], but see [25-29]. Postcopulatory preferences for genetically similar mating partners have been documented in the Arctic charr (Salvelinus alpinus) [30], the Atlantic salmon (Salmo salar) [31] and in the Peron's tree frog (Litoria peronii) [32]. These studies stress that a high possibility of hybridization in their study species accounts for the observed results [30-32]. However, it remains noteworthy that sometimes mating with a close relative is actively preferred and may even increase an individual's fitness [33-36]. This is in accordance with recent theory, as incestuous matings provide a possibility to spread genes identical by descent [37].

The threespine stickleback (Gasterosteus aculeatus) is a small externally fertilizing fish species that inhabits marine, brackish as well as freshwater habitats [38]. Postglacially, anadromous populations have frequently established new freshwater populations, presumably consisting of only a few founder individuals (see [39] for details and [40] for an example of recent colonization events in Switzerland). Due to founder effects and limited population size freshwater populations often show a reduced genetic diversity (e.g. [41,42]), increasing their probability of becoming extinct [43]. This follows the more general pattern that the allelic diversity among fishes is higher in marine populations as compared to freshwater populations (see [44]).

Recent studies on the effects of inbreeding on life history traits exclusively examined stickleback individuals from a large, genetically heterogeneous population from Texel, the Netherlands [41], revealing that they are prone to inbreeding depression. In detail, incestuous matings lowered fertilization success, hatching rate and survival of both juveniles and adults [45]. In addition, at adult stage inbred individuals had more asymmetric pectoral fins [46] and showed an altered shoaling behavior toward kin [47]. Moreover, there is strong evidence for a precopulatory inbreeding avoidance mechanism in this population as in choice experiments, female sticklebacks rejected their brothers as mating partners $[48,49]$, and inbred females had a stronger preference for symmetrical males than outbred females [50]. However, inbreeding did not affect adult males' breeding coloration or testis and sperm traits [45,51]. This might be best explained by the fact that it is difficult to detect the negative consequences of inbreeding, when homozygous individuals suffer from lethal mutations early in life and as a result a low number of inbred individuals reaches the reproductive phase (see $[45,51]$ for details).

In general, the frequency of sneaking (i.e. the stealing of fertilizations) and thus the risk of sperm competition is known to be high in sticklebacks (e.g. [52]) so that precopulatory inbreeding avoidance (see $[48,49]$ ) might not always be effective. Besides, given the severe consequences of incestuous matings (e.g. [45]) the present study aimed to investigate whether there is a postcopulatory inbreeding avoidance mechanism solely based on sperm-egg interactions in sperm competition experiments. Therefore, we used stickleback individuals originating from the same large anadromous population as described before [41] and from a small resident freshwater population (Euskirchen, Germany). Generally, we expected different selective constraints for individuals originating from a small, genetically less diverse compared to a large, genetically heterogeneous population as supported by a recent theoretical study (see [53]). In detail, a postcopulatory inbreeding avoidance mechanism might be less relevant in small populations due to purging of deleterious alleles after repeated inbreeding (e.g. [54,55]). Alternatively, inbreeding is known to enhance the extinction risk in small genetically less diverse populations (see [56]), suggesting that there might be a stronger selection for a postcopulatory inbreeding avoidance mechanism (e.g. [19,57]).

Apart from genetic compatibility [58], sperm morphology, such as sperm size, is known to be a good proxy of reproductive performance in several animal species (reviewed in $[59,60]$ ). However, throughout the literature the relationship between sperm size and fertilization success at the intraspecific level is inconsistent: negative (e.g. $[61,62])$, positive (e.g. $[63,64])$ or no (e.g. $[65,66])$ relationships have been reported. Based on the fact that there is huge between- and within-male variation in sperm morphology in the threespine stickleback (see [67]), we additionally addressed the variation of sperm size in relation to fertilization success in the present study. In externally fertilizing species, fertilization rate is not confounded by characteristics of the female reproductive tract.

\section{Methods \\ Ethics}

The study conforms to the Association for the Study of Animal Behaviour Guidelines for the use of animals in research as well as to the legal requirements of Germany. We had the permission to catch the parental generation of the F1 sticklebacks used in this study at the Euskirchen field site (local forestry department, Euskirchen, Germany). In addition, the parental generation of the F1 sticklebacks used in this study from the anadromous population (Texel, the Netherlands) was purchased from a commercial fisherman, who has the permission to catch the fish. No further licenses were needed.

\section{Experimental subjects}

Test fish from the small, genetically less diverse freshwater population used in this study originated from the F1 generation of randomly crossed wild-caught fish 
(2007, Euskirchen, Germany). Parents were only used once to avoid pseudoreplication. Offspring hatched between September 2 and October 11, 2007. During development, all fish were housed in an air-conditioned room under standardized laboratory short-day conditions (17 \pm $1^{\circ} \mathrm{C}$, day length 8L:16D). Juveniles were fed with Artemia nauplii and later on defrosted red mosquito larvae (Chironomus spec.). To stimulate reproductive behavior the light-regime was changed to long-day summer conditions $\left(17 \pm 1^{\circ} \mathrm{C}\right.$, day length 16L:8D) on June 6, 2008 . The standardized in vitro fertilization trials were conducted between June 19 and July 29, 2008.

Test fish from the large, genetically heterogeneous anadromous population (Texel, the Netherlands) used in this study were also the F1 generation of randomly crossed wild-caught fish (bred in 2008). Breeding and rearing conditions of these individuals followed a similar standardized protocol as for the freshwater population, which is described in detail in Mehlis \& Bakker [68]. In vitro fertilization trials took place between June 29 and July 23, 2009.

To validate that the $\mathrm{F} 1$ freshwater fish used in this study were genetically less diverse in comparison to the F1 anadromous fish we genotyped 34 randomly chosen unrelated individuals (17 from each population) at nine microsatellite loci ([41,69], see also Additional file 1). The results showed that the mean number of alleles per locus (A) was approximately three times higher for the anadromous population $(A=13.89)$ compared to the freshwater population $(\mathrm{A}=4.89)$ (Wilcoxon signed rank test: $\mathrm{N}=9, \mathrm{z}=-2.670, \mathrm{p}=0.008$; Table 1 ). However, both populations did not differ significantly from HardyWeinberg equilibrium (both $\mathrm{p} \geq 0.159$; Table 1 ) and inbreeding coefficient values were close to zero in both populations (freshwater: $\mathrm{F}_{\mathrm{IS}}=0.033$; anadromous: $\mathrm{F}_{\mathrm{IS}}=$ 0.035; Table 1), suggesting random mating patterns under natural conditions.

\section{In vitro fertilization trials}

For both populations, in vitro fertilization trials $\left(\mathrm{N}_{\text {freshwater }}=\right.$ $17, \mathrm{~N}_{\text {anadromous }}=22$ ) were conducted following an identical protocol. In detail, an in vitro fertilization trial consisted of two sub-trials in which sperm from the same two males were allowed to compete against each other for egg fertilization. For each sub-trial a different egg-donating female was used (see Figure 1). In one sub-trial (called main experiment) one of the two males was the female's full-sib brother. In the other sub-trial (called control experiment) the female was unrelated to both males (see also Figure 1). Males are therefore referred to as "brother" (between quotation marks as brother is only valid for the main experiment) and non-sib male from now on.

Prior to in vitro fertilization trials randomly chosen males were isolated in single tanks (30 cm length $x$ $20 \mathrm{~cm}$ width $\times 20 \mathrm{~cm}$ height) under summer conditions (see above), each equipped with a sand-filled Petri dish $(\varnothing 9 \mathrm{~cm})$ and $2 \mathrm{~g}$ of nest-building material (Vesicularia dubyana). Females used in the main experiments originated from the same laboratory-bred F1 generations (see above) whereas those used in the control experiments were wild-caught. This applies to the experiments with both the anadromous and the freshwater population. Wild-caught fish were trapped on March 27, 2008 (freshwater) and on April 3, 2009 (anadromous). All wild-caught fish were kept in mixed-sex groups of about 400-500 individuals in large outdoor tanks (750 l) with a constant supply of tap-water $\left(31 \mathrm{~min}^{-1}\right)$ and were daily fed with Chironomus spec. In both stickleback populations, reproduction takes place one year after hatching. Accordingly, the frequency distribution of fish lengths is single-peaked (MM unpublished observation) revealing that wild-caught females used in the control experiment were of the same age as F1 individuals.

Only sperm of size-matched $( \pm 2 \mathrm{~mm})$, nest-holding males were allowed to compete against each other for egg fertilization (for details concerning the experimental design see Figure 1). First, one male of the pair was killed quickly by decapitation in order to dissect the testes as sperm stripping is not possible in sticklebacks (the only exception in [70]). Directly before decapitation fish were anesthetized with a blow to the head, which is the quickest method (see also [71]). After dissection, testes were separately stored in $200 \mu \mathrm{l}$ of a non-activating medium (for mixture see [72]) for later in vitro fertilization (sperm from the left testis) and sperm morphology determination (sperm from the right testis). The same was done for the second male. To avoid sequence effects "brother" and non-sib males were killed in random order. Directly thereafter sperm number was determined for both males as described in Mehlis \& Bakker [68] to ensure that equal

Table 1 Population structure analysis

\begin{tabular}{llllllllll}
\hline Population & $\mathbf{N}$ & Loci & $\mathbf{A}$ & $\mathbf{H}_{\mathbf{e}}$ & $\mathbf{H}_{\mathbf{o}}$ & $\mathbf{F}_{\text {IS }}$ & $\mathbf{p}_{\text {HWE }}$ & $\chi_{\text {HWE }}^{2}$ & $\mathbf{d f}_{\text {HWE }}$ \\
\hline freshwater & 17 & 9 & 4.89 & 0.6686 & 0.6471 & 0.033 & 0.559 & 16.479 & 18 \\
anadromous & 17 & 9 & 13.89 & 0.9063 & 0.8758 & 0.035 & 0.159 & 23.868 & 18
\end{tabular}

Shown is a comparison of the variation of nine microsatellite markers based on 34 randomly chosen unrelated individuals (17 F1 fish from the freshwater and $17 \mathrm{~F} 1$ fish from the anadromous stickleback population) (see [41,69], and Additional file 1 for further details]. N: number of individuals typed, A: mean number of alleles per locus, $\mathrm{H}_{\mathrm{e}}$ : expected heterozygosity, $\mathrm{H}_{\mathrm{o}}$ : observed heterozygosity, $\mathrm{F}_{1 \mathrm{~s}}$ : inbreeding coefficient, and results of chi-square tests for deviation from expected proportions under Hardy-Weinberg equilibrium (HWE) (given are $\mathrm{p}$-values, $\mathrm{X}^{2}$ and degrees of freedom, $\mathrm{df}$ ). 


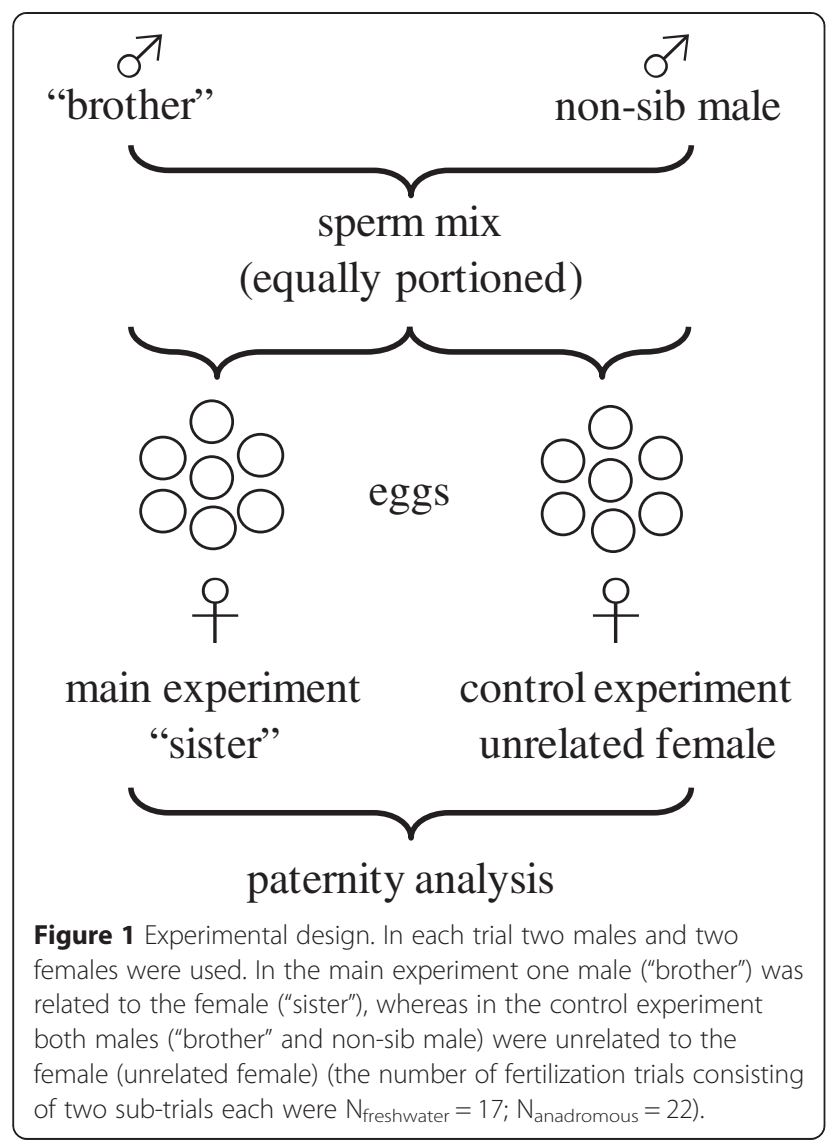

proportions of males' sperm (125,000 sperm per egg and male) were used during the fertilization process. By keeping the sperm number constant we controlled for a potential influence of sperm quantity as suggested by theory [73,74]. Immediately after both males' testes had been dissected and sperm number had been quantified, one randomly chosen gravid female (either a "sister" of one of the males (main experiment) or a female unrelated to both males (control experiment), see Figure 1) was stripped and 50 eggs were counted and placed in a small glass Petri dish that already contained $1 \mathrm{ml}$ of tap water. Using a pipette the sperm mixture (containing 125,000 sperm per egg of the "brother" and 125,000 sperm per egg of the non-sib male) was distributed over the eggs. The same was done with the other females' eggs. Again, "sisters" and unrelated females were stripped in random order to avoid sequence effects.

One hour later, the fertilization process was stopped by adding sparkling table water over the clutches; a method which has been shown not to harm the eggs but to quickly kill the sperm [75]. Eggs were placed in a small aerated container ( 1 liter) and $24 \mathrm{~h}$ later fertilization rate was checked [76] using a binocular (Leica S8AP0), before all eggs were stored in $99.8 \%$ ethanol at $-18^{\circ} \mathrm{C}$ for subsequent paternity analyses. Shortly before storage, ten randomly chosen fertilized eggs were weighed to the nearest milligram to determine the average egg mass as an indicator of female quality [77]. Females that participated in an in vitro fertilization sub-trial were marked by cutting the tip of a spine before they were returned to their holding tank in order to avoid repeated use and thus pseudoreplication. The females' spines and tissue samples from the pectoral fin of the males were separately stored in $99.8 \%$ ethanol at $-18^{\circ} \mathrm{C}$ for subsequent paternity analyses (see below).

Sperm morphology variables (head length (including mid-piece) (hl) and tail length (tl)) were determined by scanning electron microscopy (see $[51,68]$ for details). Sperm morphology variables were based on $10.56 \pm 3.74$ (mean $\pm \mathrm{SD}$ ) sperm per male for the freshwater population and on $20.57 \pm 1.99$ (mean \pm SD) sperm per male for the anadromous population.

\section{Paternity analyses}

Paternity analyses were done using four polymorphic microsatellite markers ([41,69], see also Additional file 2). DNA-samples of parents and eggs were extracted via Chelex (Bio-Rad, after [78]). The tailed primer method [79] was used for subsequent PCR (see Additional file 3 for details) and PCR-products were run on a CEQ 8800 Genetic Analysis System (Beckman Coulter) and analyzed via GenomeLabTM GeXP (version10.2). For both sub-trials (i.e. main as well as the control experiment) sub-samples of 30 eggs were genotyped. On average $29.06 \pm 1.59$ (mean \pm SD) eggs per sub-trial could be successfully assigned to one father for the freshwater population and $28.91 \pm 2.37$ (mean \pm SD) for the anadromous population, respectively. In total 2260 eggs were genotyped (freshwater: 988 eggs; anadromous: 1272 eggs).

\section{Statistical analyses}

Non-parametric statistics were used as data significantly deviated from normal distribution according to Kolmogorov-Smirnov tests with Lilliefors correction. Data were analyzed in SPSS 15.0. Test probabilities are two-tailed throughout. Linear mixed-effect models were fitted using the 'lme' function in the "nlme" library of the R 3.0.2 statistical package. The differences in fertilization success ("brother" minus non-sib male) were calculated for each population and used as dependent variable, the sub-trial (main or control experiment) was included as explanatory variable and trial number was defined as random factor and never removed to control for the paired study design.

An additional linear mixed-effect model was run to elucidate whether any sperm morphology trait was related to fertilization success. Therefore, differences in fertilization success ("brother" minus non-sib male) were again used as dependent variable and averaged values for 
males' sperm tail length respectively the sperm head to tail length ratio (hl/tl, see [80]) were separately included as explanatory variable. Moreover, two different males as well as two females were used for one in vitro fertilization trial. Thus, males' body size and females' egg mass were included as explanatory variables and never removed to control for potential differences in males' phenotype and females' egg quality. Additionally to the trial number, the study population was defined as random factor. Both random factors were left in the model to control for the paired study design as well as for potential population differences (see Additional file 4 for an overview of all fitted models).

Tests of significance were based on likelihood-ratio tests and in all models explanatory variables were stepwise removed in the order of statistical relevance. The residuals of the best explaining models did not significantly deviate from normal distributions according to Kolmogorov-Smirnov tests.

\section{Results}

The proportion of fertilized eggs did not differ significantly between the main and the control experiment (Wilcoxon signed rank test: $\mathrm{N}_{\text {freshwater }}=17, \mathrm{z}=-1.436$, $\left.\mathrm{p}=0.151 ; \quad \mathrm{N}_{\text {anadromous }}=22, \mathrm{z}=-0.714, \mathrm{p}=0.475\right)$. In addition, the relative number of fertilized eggs ("brother" minus non-sib male) did not differ significantly between main and control experiment; neither in the freshwater population ("Ime", $\mathrm{N}_{\text {freshwater }}=17, x^{2}=0.148, \mathrm{p}=0.700$; Figure 2) nor in the anadromous population ("lme", $\mathrm{N}_{\text {anadromous }}=22, \mathrm{x}^{2}=0.229, \mathrm{p}=0.632$; Figure 2), indicating that no postcopulatory inbreeding avoidance mechanism exists in both populations. However, males that were successful in the control experiment were also the winner in the main experiment and vice versa (Pearson correlation: $\mathrm{N}_{\text {freshwater }}=17, \mathrm{r}_{\mathrm{P}}=0.961, \mathrm{p}<0.001 ; \mathrm{N}_{\text {anadromous }}=22, \mathrm{r}_{\mathrm{P}}=$ 0.950, $\mathrm{p}<0.001$; Figure 3).

As in both populations postcopulatory inbreeding avoidance was absent, data were pooled for further analyses. The results showed that competitive fertilization success was significantly predicted by sperm quality (tail length: "Ime", $\mathrm{N}=39, \mathrm{X}^{2}=4.909, \mathrm{p}=0.027$; head to tail length ratio: "Ime", $\mathrm{N}=39, \mathrm{x}^{2}=4.398, \mathrm{p}=0.036$; Table 2). Fertilization success was significantly negatively correlated with tail length (Spearman rank correlation: $\mathrm{N}=$ $39, r_{S}=-0.349, p=0.030$ ) and significantly positively correlated with head to tail length ratio (Spearman rank correlation: $\mathrm{N}=39, \mathrm{r}_{\mathrm{S}}=0.319, \mathrm{p}=0.048$; Figure 4).

\section{Discussion}

Both in a genetically heterogeneous, anadromous stickleback population and in a genetically impoverished, freshwater stickleback population, we found no evidence for a postcopulatory inbreeding avoidance mechanism. Males

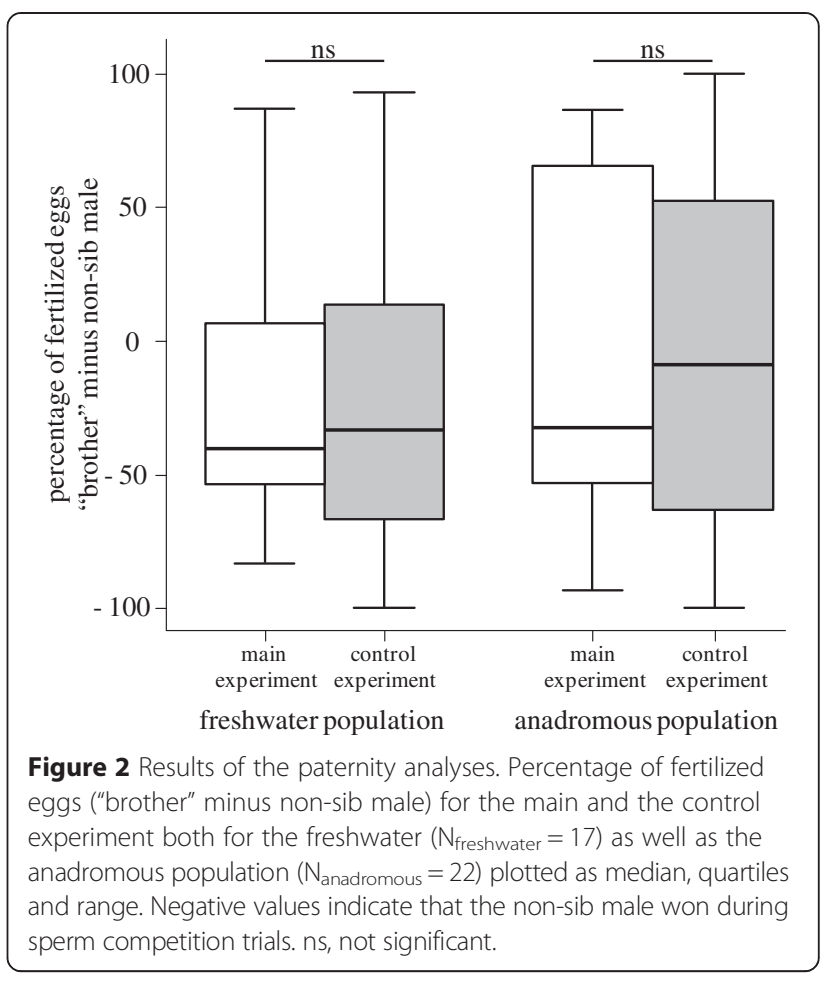

related and unrelated to the female, had on average equal paternity chances in sperm competition experiments. Paternity was related to the size of a male's sperm instead.

Previous studies on sticklebacks of the present anadromous population have shown a precopulatory inbreeding avoidance mechanism as females preferred to mate with

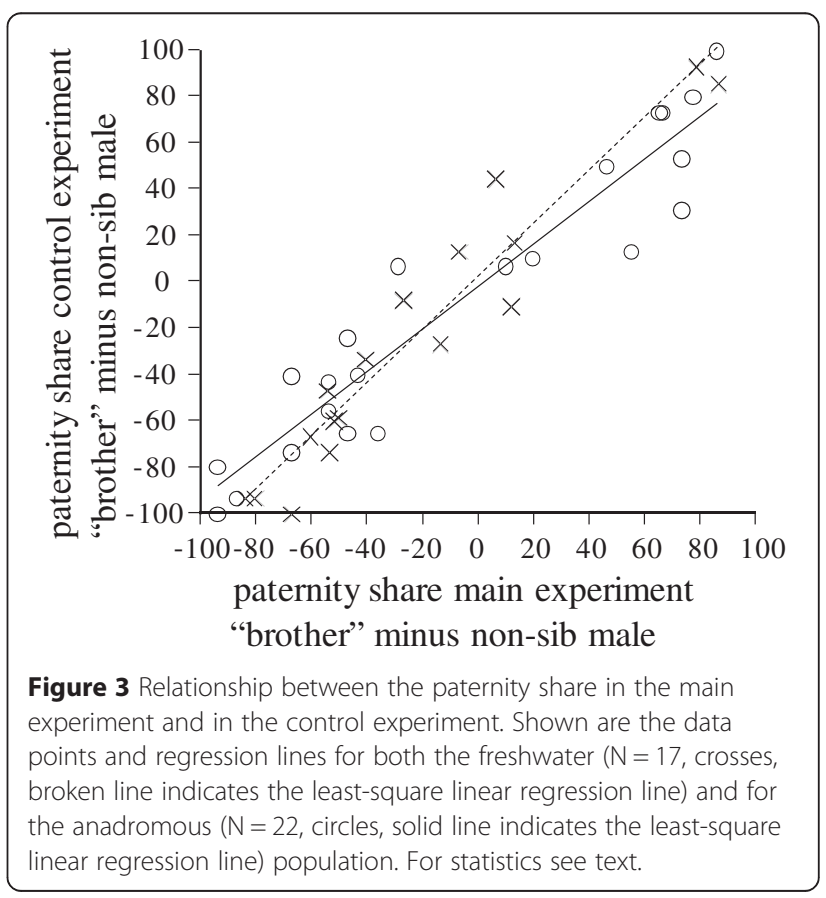


Table 2 Sperm morphology traits in relation to fertilization success

\section{Dependent variable}

Competitive fertilization success

\begin{tabular}{lll}
\hline Explanatory variable & $\mathbf{X}^{\mathbf{2}}$ & $\mathbf{p}$-value \\
\hline Tail length & 4.909 & 0.027 \\
Head to tail length ratio & 4.398 & 0.036
\end{tabular}

Both sperm tail length and head to tail length ratio significantly explain fertilization success in the in vitro sperm competition trials with fish from a freshwater and an anadromous stickleback population. Given are p-values and $x^{2}$. See text for details.

unrelated males [48,49]. In addition, males from the anadromous population released fewer sperm during incestuous matings (MM, LK Hilke and TCMB unpublished data). Hence, at least in the anadromous population both sexes seem to avoid the severe consequences of inbreeding at the precopulatory stage, which may explain the lack of a postcopulatory inbreeding avoidance mechanism as observed in the present study (see [81] for a comparable result). Whether this also applies to individuals originating from the small, genetically less diverse freshwater population is unknown. Indeed, in small populations the risk to mate with a partner by chance that carries genes identical by descent is obviously higher. By using in vitro fertilization techniques we avoided confounding influences of precopulatory differences in behavior and were thus able to investigate the existence of an inbreeding avoidance mechanism exclusively based on the postcopulatory level. Irrespective of population size and thus contrary to our expectations, we did not find any evidence for a postcopulatory inbreeding avoidance mechanism in the present study. However, previous

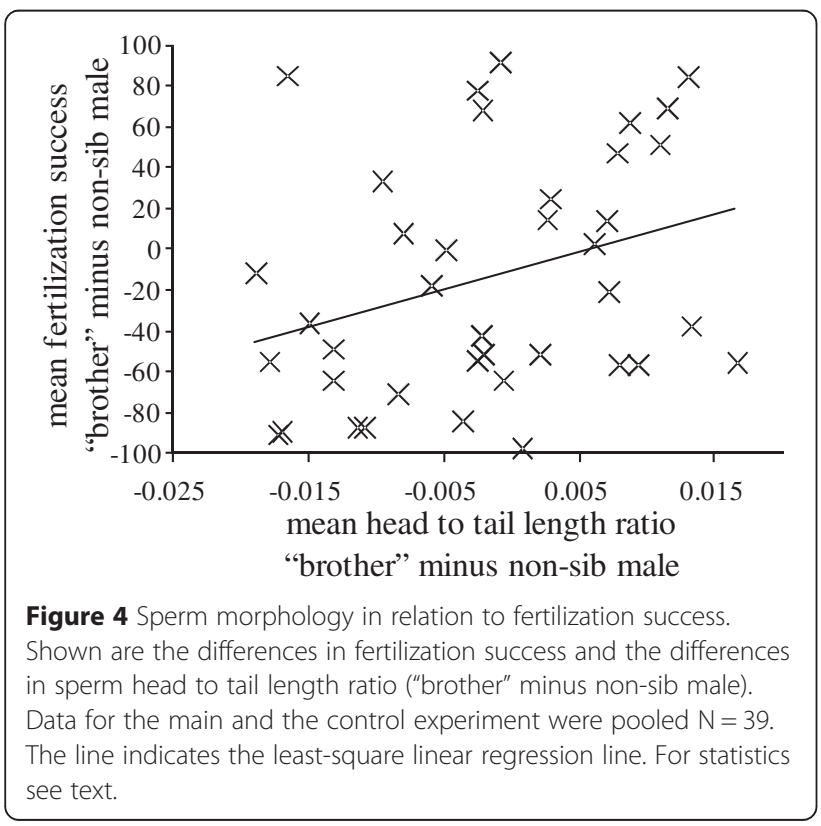

studies showed that in guppies (Poecilia reticulata) and in lake trouts (Salvelinus namaycush) sperm swam faster in ovarian fluid of unrelated females indicating fitness benefits (see $[82,83])$. Nevertheless, a postcopulatory inbreeding avoidance exclusively based on sperm-egg interactions seems to be absent in sticklebacks.

An individual's ability to select a mating partner that carries good or compatible genes could lead to indirect genetic benefits [84-86]. In detail, selection for "good genes" (additive genetic effects for increased survival) leads to directional selection, i.e. each female within a population should mate with males that carry these good genes. Selection for compatible genes (non-additive genetic variation) does not result in directional selection. For example, a high degree of relatedness between mating partners might represent one reason of genetic incompatibility $[87,88]$. In the present study the success of a male in the competitive fertilization trials was exclusively based on sperm quality (in terms of sperm morphology as we were not able to measure sperm velocity) in both populations. Hence, the results suggest a directional selection for a "superior" male phenotype independent of genetic incompatibility (see [27] for a comparable result in mallards). A recent study by Eizaguirre et al. [89] supported the good gene hypothesis of sexual selection in sticklebacks. In semi-natural enclosures, females preferred to mate with males with a specific MHC-haplotype, which was related to indirect fitness benefits as these males were larger and had a higher resistance to a common parasite (Gyrodactylus spec.) [89].

Between-male variation in stickleback sperm design (see also [67]) mainly consists of variation in sperm tail length, as it accounts for up to $90 \%$ of the total sperm length. Sperm with a longer tail (i.e. smaller head to tail length ratio, defined after [80]) swim in a more linear path and sperm that swim in a linear path were shown to swim faster [90], suggesting that these sperm might encounter an unfertilized egg more rapidly (see also [91]). In sperm competition, one would thus expect an advantage for longer sperm. Counterintuitively, in the present study relatively shorter sperm (and sperm with a relatively large head to tail length ratio) won the race for egg fertilization during competitive in vitro fertilization trials. A recent in vitro study by Bakker et al. [67] provides a convincing explanation. By experimentally manipulating fertilization duration Bakker et al. [67] showed that sperm with longer tails (i.e. relatively small head to tail length ratio) fertilize faster when the fertilization process was stopped 60 seconds after the start of the sperm release. This resulted in a positive correlation between sperm size and fertilization success whereas a negative correlation was found when the fertilization process was stopped after 600 seconds [67]. Thus, sperm size seems to be traded off against sperm longevity in our study species (see [67] for 
details). Additionally, in sticklebacks, complete clutch fertilization takes atypically long for an externally fertilizing species (up to $10 \mathrm{~min}$, [75]) and the sperm motility period is prolonged by the presence of ovarian fluid (up to several hours, [92]).

To ensure high fertilization rates under laboratory conditions (on average $98 \%$ for the anadromous population and $96 \%$ for the freshwater population) we decided to stop the fertilization process after 60 minutes in the present study. This might account for the observed negative correlation between sperm size and fertilization success (see also [67] for details). As mentioned above, the relationship between sperm size and fertilization success is ambiguous, showing no general pattern: negative (e.g. $[61,62])$, positive (e.g. $[63,64])$ or absent (e.g. $[65,66])$. Generally, this topic is controversial and even within the same species the relationship between sperm morphology traits and sperm velocity in particular seems to be dynamic and influenced by many factors. Rick et al. [93], for example, showed that in sticklebacks, sperm velocity is negatively affected by increased levels of ambient UV light whereas sperm morphology traits remain unaffected.

\section{Conclusion}

There is no evidence for a postcopulatory inbreeding avoidance mechanism in our study species, irrespective of population size. Instead, sperm quality traits predicted paternity success during competitive fertilization trials, indicating that this trait is under strong sexual selection, presumably forced by the high risk of sperm competition under natural conditions.

\section{Additional files}

Additional file 1: List and PCR conditions of the microsatellite markers used for population structure analysis.

Additional file 2: Details of the microsatellite markers used for paternity analyses.

Additional file 3: PCR conditions of the microsatellite markers used for paternity analyses.

Additional file 4: Overview of all fitted linear mixed-effect models.

\section{Competing interests}

The authors declare that they have no competing interests.

\section{Authors' contributions}

MM, AKR and TCMB planned the study. The in vitro fertilization trials were done by AKR (freshwater population) and MM (anadromous population). MM analyzed the data and wrote the manuscript, supported by AKR and TCMB. All authors read and approved the final manuscript.

\section{Acknowledgements}

We are grateful to the "Bakker"-research-group, especially to Claudia Schütte and Dagmar Wenzel for paternity analyses. Sabine Sachau is kindly acknowledged for breeding and rearing the different family groups of the freshwater population. We acknowledge the permission of Jürgen Wittler to catch sticklebacks at the Euskirchen field site and we would like to thank Jan Hottentot for catching the anadromous sticklebacks. Dagmar Wenzel, Arne
Schmidt, Stefanie Gierszewski, Anh-Phong Nguyen and Erika Müller-Schulte are acknowledged for help in measuring SEM images. Joachim G. Frommen, Ingolf P. Rick and Timo Thünken gave thoughtful comments on an earlier version of this manuscript. This research was funded by the Deutsche Forschungsgemeinschaft (BA 2885/4-1).

Received: 23 December 2014 Accepted: 15 April 2015

Published online: 26 April 2015

\section{References}

1. Charlesworth D, Charlesworth B. Inbreeding depression and its evolutionary consequences. Annu Rev Ecol Syst. 1987;18:237-68.

2. Michalczyk $Ł$, Martin OY, Millard AL, Emerson BC, Gage MJG. Inbreeding depresses sperm competitiveness, but not fertilization or mating success in male Tribolium castaneum. Proc R Soc Lond B. 2010;277:3483-91.

3. van Lieshout E, Tomkins JL, Simmons LW. Heat stress but not inbreeding affects offensive sperm competitiveness in Callosobruchus maculatus. Ecol Evol. 2013:3:2859-66.

4. Zajitschek SRK, Lindholm AK, Evans JP, Brooks RC. Experimental evidence that high levels of inbreeding depress sperm competitiveness. J Evol Biol. 2009;22:1338-45

5. Keller LF, Waller DM. Inbreeding effects in wild populations. Trends Ecol Evol. 2002;17:230-41.

6. Markert JA, Champlin DM, Gutjahr-Gobell R, Grear JS, Kuhn A, McGreevy TJ, et al. Population genetic diversity and fitness in multiple environments. BMC Evol Biol. 2010:10:205.

7. Bouzat JJ. Conservation genetics of population bottlenecks: the role of chance, selection, and history. Conserv Genet. 2010;11:463-78.

8. Saccheri I, Kuussaari M, Kankare M, Vikman P, Fortelius W, Hanski I. Inbreeding and extinction in a butterfly metapopulation. Nature. 1998:392:491-4.

9. Boakes EH, Wang J, Amos W. An investigation of inbreeding depression and purging in captive pedigreed populations. Heredity. 2007;98:172-82.

10. Pusey A, Wolf M. Inbreeding avoidance in animals. Trends Ecol Evol. 1996;11:201-6.

11. Hoffman JI, Forcada J, Trathan PN, Amos W. Female fur seals show active choice for males that are heterozygous and unrelated. Nature. 2007:445:912-4.

12. Huang MH, Caillaud MC. Inbreeding avoidance by recognition of close kin in the pea aphid, Acyrthosiphon pisum. J Insect Sci. 2012;12:1-13.

13. Lihoreau M, Zimmer C, Rivault C. Mutual mate choice: when it pays both sexes to avoid inbreeding. PLoS One. 2008;3, e3365.

14. Gerlach G, Lysiak N. Kin recognition and inbreeding avoidance in zebrafish, Danio rerio, is based on phenotype matching. Anim Behav. 2006;71:1371-7.

15. Tuni $C$, Beveridge $M$, Simmons LW. Female crickets assess relatedness during mate guarding and bias storage of sperm towards unrelated males J Evol Biol. 2013;26:1261-8.

16. Tregenza T, Wedell N. Polyandrous females avoid costs of inbreeding. Nature. 2002;415:71-3.

17. Simmons LW, Beveridge M, Wedell $N$, Tregenza T. Postcopulatory inbreeding avoidance by female crickets only revealed by molecular markers. Mol Ecol. 2006;15:3817-24.

18. Bretman A, Wedell N, Tregenza T. Molecular evidence of post-copulatory inbreeding avoidance in the field cricket Gryllus bimaculatus. Proc R Soc Lond B. 2004;271:159-64

19. Brekke P, Wang J, Bennett PM, Cassey P, Dawson DA, Horsburgh GJ, et al. Postcopulatory mechanisms of inbreeding avoidance in the island endemic hihi (Notiomystis cincta). Behav Ecol. 2012;23:278-84.

20. Firman RC, Simmons LW. Polyandry facilitates postcopulatory inbreeding avoidance in house mice. Evolution. 2008;62:603-11.

21. Welke K, Schneider J. Inbreeding avoidance through cryptic female choice in the cannibalistic orb-web spider Argiope lobata. Behav Ecol. 2009;20:1056-62

22. Harano T, Katsuki M. Female seed beetles, Callosobruchus chinensis, remate more readily after mating with relatives. Anim Behav. 2012;83:1007-10.

23. Stockley P. Sperm selection and genetic incompatibility: does relatedness of mates affect male success in sperm competition? Proc R Soc Lond B. 1999;266:1663-9.

24. Fitzpatrick JL, Evans JP. Postcopulatory inbreeding avoidance in guppies. J Evol Biol. 2014;27:2585-94. 
25. Ala-Honkola O, Manier MK, Lüpold S, Pitnick S. No evidence for postcopulatory inbreeding avoidance in Drosophila melanogaster. Evolution. 2011;65:2699-705.

26. Ala-Honkola O, Tuominen L, Lindström K. Inbreeding avoidance in a poeciliid fish (Heterandria formosa). Behav Ecol Sociobiol. 2010;64:1403-14.

27. Denk AG, Holzmann A, Peters A, Vermeirssen ELM, Kempenaers B. Paternity in mallards: effects of sperm quality and female sperm selection for inbreeding avoidance. Behav Ecol. 2005;16:825-33.

28. Evans JP, Rutstein AN. Postcopulatory sexual selection favours intrinsically good sperm competitors. Behav Ecol Sociobiol. 2008:62:1167-73.

29. Jennions MD, Hunt J, Graham R, Brooks R. No evidence for inbreeding avoidance through postcopulatory mechanisms in the black field cricket, Teleogryllus commodus. Evolution. 2004;58:2472-7.

30. Liljedal S, Rudolfsen G, Folstad I. Factors predicting male fertilization success in an external fertilizer. Behav Ecol Sociobiol. 2008;62:1805-11.

31. Yeates SE, Einum S, Fleming IA, Megens HJ, Stet RJM, Hindar K, et al. Atlantic salmon eggs favour sperm in competition that have similar major histocompatibility alleles. Proc R Soc Lond B. 2009;276:559-66.

32. Sherman $\mathrm{CDH}$, Wapstra E, Uller T, Olsson M. Males with high genetic similarity to females sire more offspring in sperm competition in Peron's tree frog Litoria peronii. Proc R Soc Lond B. 2008;275:971-8.

33. Keane B, Creel SR, Waser PM. No evidence of inbreeding avoidance or inbreeding depression in a social carnivore. Behav Ecol. 1996;7:480-9.

34. Thünken T, Bakker TCM, Baldauf SA, Kullmann H. Active inbreeding in a cichlid fish and its adaptive significance. Curr Biol. 2007;17:225-9.

35. Peer K, Taborsky M. Outbreeding depression, but no inbreeding depression in haplodiploid Ambrosia beetles with regular sibling mating. Evolution. 2005:59:317-23.

36. Kuriwada T, Kumano N, Shiromoto K, Haraguchi D. The effect of inbreeding on mating behaviour of West Indian sweet potato weevil Euscepes postfasciatus. Ethology. 2011;117:822-8.

37. Kokko H, Ots I. When not to avoid inbreeding. Evolution. 2006;60:467-75.

38. Wootton RJ. The biology of the sticklebacks. London: Academic; 1976

39. Bell MA, Foster SA. Introduction to the evolutionary biology of the threespine stickleback. In: Bell MA, Foster SA, editors. The evolutionary biology of the threespine stickleback. Oxford: Oxford University Press; 1994. p. 1-27.

40. Lucek K, Sivasundar A, Roy D, Seehausen O. Repeated and predictable patterns of ecotypic differentiation during a biological invasion: lake-stream divergence in parapatric Swiss stickleback. J Evol Biol. 2013;26:2691-709.

41. Heckel G, Zbinden M, Mazzi D, Kohler A, Reckeweg G, Bakker TCM, et al. Microsatellite markers for the three-spined stickleback (Gasterosteus aculeatus L) and their applicability in a freshwater and an anadromous population. Conserv Genet. 2002:3:79-81.

42. Raeymaekers J, Maes G, Audenaert E, Volckaert F. Detecting Holocene divergence in the anadromous-freshwater three-spined stickleback (Gasterosteus aculeatus) system. Mol Ecol. 2005;14:1001-14.

43. Pease CM, Lande R, Bull JJ. A model of population growth, dispersal and evolution in a changing environment. Ecology. 1989;70:1657-64.

44. DeWoody JA, Avise JC. Microsatellite variation in marine, freshwater and anadromous fishes compared with other animals. J Fish Biol. 2000;56:461-73.

45. Frommen JG, Luz C, Mazzi D, Bakker TCM. Inbreeding depression affects fertilization success and survival but not breeding coloration in threespine sticklebacks. Behaviour. 2008;145:425-41.

46. Mazzi D, Largiadèr CR, Bakker TCM. Inbreeding and developmental stability in three-spined sticklebacks (Gasterosteus aculeatus L.). Heredity. 2002:89:293-9.

47. Frommen JG, Mehlis M, Brendler C, Bakker TCM. Shoaling decisions in threespined sticklebacks (Gasterosteus aculeatus) - familiarity, kinship and inbreeding. Behav Ecol Sociobiol. 2007:61:533-9.

48. Frommen JG, Bakker TCM. Inbreeding avoidance through non-random mating in sticklebacks. Biol Lett. 2006;2:232-5.

49. Mehlis M, Bakker TCM, Frommen JG. Smells like sib spirit: kin recognition in three-spined sticklebacks (Gasterosteus aculeatus) is mediated by olfactory cues. Anim Cogn. 2008;11:643-50.

50. Mazzi D, Künzler R, Largiadèr CR, Bakker TCM. Inbreeding affects female preference for symmetry in computer-animated sticklebacks. Behav Genet. 2004;34:417-24.

51. Mehlis M, Frommen JG, Rahn AK, Bakker TCM. Inbreeding in sticklebacks (Gasterosteus aculeatus L.): effects on testis and sperm traits. Biol J Linn Soc. 2012;107:510-20.
52. Largiadèr CR, Fries V, Bakker TCM. Genetic analysis of sneaking and egg-thievery in a natural population of the three-spined stickleback (Gasterosteus aculeatus L.) Heredity. 2001;86:459-68.

53. Lanfear R, Kokko H, Eyre-Walker A. Population size and the rate of evolution. Trends Ecol Evol. 2014;29:33-41.

54. Hoelzel AR, Halley J, Obrien SJ, Campagna C, Arnbom T, O'Brien SJ, et al. Elephant seal genetic variation and the use of simulation models to investigate historical population bottlenecks. J Hered. 1993;84:443-9.

55. Jarzebowska M, Radwan J. Sexual selection counteracts extinction of small populations of the bulb mites. Evolution. 2010;64:1283-9.

56. Bijlsma R, Bundgaard J, Boerema AC. Does inbreeding affect the extinction risk of small populations?: predictions from Drosophila. J Evol Biol. 2000;13:502-14.

57. Frasier TR, Gillett RM, Hamilton PK, Brown MW, Kraus SD, White BN. Postcopulatory selection for dissimilar gametes maintains heterozygosity in the endangered North Atlantic right whale. Ecol Evol. 2013;3:3483-94.

58. Tregenza T, Wedell N. Genetic compatibility, mate choice and patterns of parentage: invited review. Mol Ecol. 2000;9:1013-27.

59. Gomendio M, Roldan ERS. Sperm competition influences sperm size in mammals. Proc R Soc Lond B. 1991;243:181-5.

60. Snook RR. Sperm in competition: not playing by the numbers. Trends Ecol Evol. 2005;20:46-53.

61. Gage MJG, Morrow EH. Experimental evidence for the evolution of numerous, tiny sperm via sperm competition. Curr Biol. 2003;13:754-7.

62. García-González F, Simmons LW. Shorter sperm confer higher competitive fertilization success. Evolution. 2007:61:816-24.

63. LaMunyon CW, Ward S. Evolution of sperm size in nematodes: sperm competition favours larger sperm. Proc R Soc Lond B. 1999;266:263-7.

64. Oppliger A, Naciri Graven Y, Ribi G, Hosken DJ. Sperm length influences fertilization success during sperm competition in the snail Viviparus ater. Mol Ecol. 2003:12:485-92.

65. Morrow EH, Gage MJG. Sperm competition experiments between lines of crickets producing different sperm lengths. Proc $R$ Soc Lond B. 2001;268:2281-6

66. Simmons LW, Wernham J, Garcia Gonzalez F, Kamien D. Variation in paternity in the field cricket Teleogryllus oceanicus: no detectable influence of sperm numbers or sperm length. Behav Ecol. 2003;14:539-45.

67. Bakker TCM, Hollmann M, Mehlis M, Zbinden M. Functional variation of sperm morphology in sticklebacks. Behav Ecol Sociobiol. 2014;68:617-27.

68. Mehlis M, Bakker TCM. Male reproductive traits of full-sibs of different age classes in three-spined sticklebacks (Gasterosteus aculeatus). SpringerPlus. 2013;2:175.

69. Largiadèr CR, Fries V, Kobler B, Bakker TCM. Isolation and characterization of microsatellite loci from the three-spined stickleback (Gasterosteus aculeatus L.) Mol Ecol. 1999:8:342-4.

70. de Fraipont M, FitzGerald GJ, Guderley H. Age-related differences in reproductive tactics in the three-spined stickleback, Gasterosteus aculeatus. Anim Behav. 1993:46:961-8.

71. Rick IP, Modarressie R, Bakker TCM. Male three-spined sticklebacks reflect in ultraviolet light. Behaviour. 2004;141:1531-41.

72. Fauvel C, Savoye O, Dreanno C, Cosson J, Suquet M. Characteristics of sperm of captive seabass in relation to its fertilization potential. J Fish Biol. 1999;54:356-69.

73. Parker GA. Why are there so many tiny sperm? Sperm competition and the maintenance of two sexes. J Theor Biol. 1982;96:281-94.

74. Parker GA. Sperm competition games: raffles and roles. Proc R Soc Lond B. 1990;242:120-6.

75. Bakker TCM, Zbinden M, Frommen JG, Weiss A, Largiadèr CR. Slow fertilization of stickleback eggs: the result of sexual conflict? BMC Ecol. 2006;6:7.

76. Swarup H. Stages in the development of the stickleback Gasterosteus aculeatus (L.). J Embryol Exp Morphol. 1958;6:373-83.

77. Bakker TCM, Mundwiler B. Female mate choice and male red coloration in a natural three-spined stickleback (Gasterosteus aculeatus) population. Behav Ecol. 1994:5:74-80

78. Estoup A, Largiadèr CR, Perrot E, Chourrout D. Rapid one-tube DNA extraction for reliable PCR detection of fish polymorphic markers and transgenes. Mol Mar Biol Biotechnol. 1996;5:295-8.

79. Schuelke M. An economic method for the fluorescent labeling of PCR fragments. Nat Biotechnol. 2000;18:233-4.

80. Humphries S, Evans JP, Simmons LW. Sperm competition: linking form to function. BMC Evol Biol. 2008:8:319. 
81. Liu X, Tu X, He H, Chen C, Xue F. Evidence for inbreeding depression and pre-copulatory, but not post copulatory inbreeding avoidance in the cabbage beetle Colaphellus bowringi. PLoS One. 2014;9, e94389.

82. Butts IAE, Johnson K, Wilson CC, Pitcher TE. Ovarian fluid enhances sperm velocity based on relatedness in lake trout, Salvelinus namaycush. Theriogenology. 2013;78:2105-9.

83. Gasparini C, Pilastro A. Cryptic female preference for genetically unrelated males is mediated by ovarian fluid in the guppy. Proc R Soc Lond B. 2011;278:2495-501.

84. Neff B, Pitcher T. Genetic quality and sexual selection: an integrated framework for good genes and compatible genes. Mol Ecol. 2005;14:19-38.

85. Andersson M. Sexual selection. Princeton University Press: Princeton; 1994.

86. Mays HL, Hill GE. Choosing mates: good genes versus genes that are a good fit. Trends Ecol Evol. 2004;19:554-9.

87. Crnokrak P, Roff DA. Inbreeding depression in the wild. Heredity. 1999;83:260-70.

88. DeRose MA, Roff DA. A comparison of inbreeding depression in life-history and morphological traits in animals. Evolution. 1999;53:1288-92.

89. Eizaguirre C, Yeates SE, Lenz TL, Kalbe M, Milinski M. MHC-based mate choice combines good genes and maintenance of MHC polymorphism. Mol Ecol. 2009;18:3316-29.

90. Mehlis M, Hilke LK, Bakker TCM. Attractive males have faster sperm in three-spined sticklebacks Gasterosteus aculeatus. Curr Zool. 2013;59:761-8.

91. Pizzari T, Parker GA. Sperm competition and sperm phenotype. In: Birkhead TR, Hosken DJ, Pitnick S, editors. Sperm biology: an evolutionary perspective. San Diego: Academic; 2009. p. 207-45.

92. Elofsson H, McAllister BG, Kime DE, Mayer I, Borg B. Long lasting stickleback sperm; is ovarian fluid a key to success in fresh water? J Fish Biol. 2003;63:240-53.

93. Rick IP, Mehlis M, Eßer E, Bakker TCM. The influence of ambient ultraviolet light on sperm quality and sexual ornamentation in three-spined sticklebacks (Gasterosteus aculeatus). Oecologia. 2014;174:393-402.

\section{Submit your next manuscript to BioMed Central and take full advantage of:}

- Convenient online submission

- Thorough peer review

- No space constraints or color figure charges

- Immediate publication on acceptance

- Inclusion in PubMed, CAS, Scopus and Google Scholar

- Research which is freely available for redistribution 